\title{
Antimicrobial resistance among bacteria isolated from urinary tract infections in females in Namibia, 2016-2017
}

Erastus H. Haindongo ${ }^{1,2^{*}}$ D , Binta Funtua ${ }^{3}$, Boni Singu ${ }^{3}$, Marius Hedimbi ${ }^{1}$, Francis Kalemeera ${ }^{3}$, Jana Hamman ${ }^{4}$, Olli Vainio ${ }^{5}$, Antti J. Hakanen ${ }^{2,6}$ and Jaana Vuopio ${ }^{2,6}$

\begin{abstract}
Background: The emergence of antimicrobial resistance (AMR) among bacterial pathogens demands a local understanding of the epidemiological situation. This information is needed both for clinical treatment decision-making purposes as well as for the revision of current care guidelines. Clinical AMR data from Namibia is sparse, whilst urinary tract infections remain not only widespread but they disproportionally affect females. This paper aims to describe the national antimicrobial resistance situation of major bacterial uropathogens in females within the 14 Namibian regions.

Method: Retrospective countrywide information on clinical urine cultures performed in females in Namibia in 2016-2017 was obtained from the national public health laboratory, Namibia Institute of Pathology (NIP). The data set included both microbiological findings as well as antimicrobial susceptibility test (AST) results. The AST was done as per the Clinical and Laboratory Standards Institute (CLSI) guidelines. Resistance to 3rd generation cephalosporins was indicative of Extended Spectrum-ß-lactamase (ESBL) production. Data analysis was done with WHONET using expert interpretation rules.
\end{abstract}

Results: In total, 22,259 urinary cultures were performed, of which 13,673 (61.4\%) were culture positive. Gram-negative bacterial species accounted for $72.6 \%$ of the findings. The most common pathogens identified were Escherichia coli, Klebsiella pneumoniae and Proteus mirabilis. Most of these were from young females, with a median age ranging from 28 to 32 years for the various pathogens. Resistance to ampicillin was 77.7\% in E. coli and 84.9\% in K. pneumoniae. In E. coli, resistance to $1^{\text {st }}$ line empiric therapy antibiotic, nitrofurantoin, was below $13 \%$, except for one region that showed 59.2\% resistance. Resistance to third generation cephalosporin (3GC) was used as a proxy for ESBL production. By year 2017, 3GC resistance was 22\%, 31.4\% and 8.3\% for E. coli, K. pneumoniae and P. mirabilis, respectively.

Conclusion: We report high resistance to ampicillin, quinolones and sulfamethoxazole-trimethoprim amongst $E$. coli. Resistance rates to third-generation cephalosporins was also concerningly high at $22 \%$. Resistance to carbapenems was low. However, superiority of nitrofurantoin was found, which provides rational support for the usefulness of nitrofurantoin as an empiric therapy regimen for the treatment of urinary tract infections in this setting.

Keywords: Antimicrobial resistance, Urinary tract infections, Female, Escherichia coli, Uropathogens, Namibia

*Correspondence: ehaindongo@unam.na

1 School of Medicine, Faculty of Health Sciences, University of Namibia, Windhoek, Namibia

Full list of author information is available at the end of the article

\section{Background}

Antimicrobial resistance (AMR) is an increasing global health issue that generally threatens public health $[1,2]$. Urinary tract infections (UTI) are common and disproportionally affect women [3-5], with at least 150 million original author(s) and the source, provide a link to the Creative Commons licence, and indicate if changes were made. The images or other third party material in this article are included in the article's Creative Commons licence, unless indicated otherwise in a credit line to the material. If material is not included in the article's Creative Commons licence and your intended use is not permitted by statutory regulation or exceeds the permitted use, you will need to obtain permission directly from the copyright holder. To view a copy of this licence, visit http://creativecommons.org/licenses/by/4.0/. The Creative Commons Public Domain Dedication waiver (http://creativeco mmons.org/publicdomain/zero/1.0/) applies to the data made available in this article, unless otherwise stated in a credit line to the data. 
infections annually [6]. Resistance to empirical antimicrobial therapeutics has reportedly increased [7-10], particularly amongst gram-negative bacteria [11].

Continuous surveillance is especially needed in low and middle-income countries due to their high burden of infections. Surveillance carries the benefit of informing therapy guidelines $[12,13]$. It is thus important that both surveillance and reporting are standardized [14] to allow for comparability across settings.

Namibia's surveillance capacity for resistant pathogens needs strengthening [15]. Furthermore, reports on antimicrobial resistance from Namibia are also limited $[16,17]$ and the resistance situation of many pathogenic isolates from different specimen types have not been described.

This study reports on the antimicrobial resistance situation of selected pathogenic micro-organisms causing UTI in females using retrospective laboratory AST surveillance data gathered from the Namibian public health laboratory service, the Namibia Institute of Pathology (NIP).

\section{Aim/objectives}

The aim was to describe the national antimicrobial resistance situation of common uropathogens in Namibian females.

\section{Materials and methods}

\section{Study setting: urine specimen collection}

Specimens were obtained from both in- and out-patients presenting with clinical symptoms indicative of a possible UTI and were obtained before the start of antimicrobial therapy.

\section{Bacterial isolation and identification}

The culture positivity cut-off was $\geq 10^{3} \mathrm{CFU} / \mathrm{ml}$, following 18-48 $\mathrm{h}$ of incubating an inoculated media plate at $37{ }^{\circ} \mathrm{C}$ aerobically. Cultures with 4 or more organisms were classified as contaminated specimens. Isolate identifications were done using Analytical Profile Index (APIbioMériuex, Marcy l'Etoile, France) 10S or 20E GNB and VITEK $^{\circledR} 2$ XL (API-bioMériuex, Marcy l'Etoile, France) GN cards.

\section{Antimicrobial susceptibility testing (AST) procedure}

AST was performed in accordance with the CLSI M100 ED26 \& ED27 guidelines. At the NIP Central Laboratory in Windhoek, AST was performed with the commercial VITEK $^{\circledR} 2$ XL system with AST N255 cards and at the peripheral laboratories with the Kirby-Bauer disk diffusion method.

The AST disks were: amoxicillin-clavulanic acid $(20 / 10 \mu \mathrm{g})$, ampicillin $(10 \mu \mathrm{g})$, cefepime $(30 \mu \mathrm{g})$, cefotaxime $(30 \mu \mathrm{g})$, ceftazidime $(30 \mu \mathrm{g})$, ceftriaxone $(30 \mu \mathrm{g})$, cefuroxime $(30 \mu \mathrm{g})$, cephalothin $(30 \mu \mathrm{g})$, gentamicin $(10 \mu \mathrm{g})$, imipenem $(10 \mu \mathrm{g})$, nalidixic acid $(30 \mu \mathrm{g})$, nitrofurantoin $(300 \mu \mathrm{g})$, ofloxacin $(5 \mu \mathrm{g})$, piperacillintazobactam $(100 / 10 \mu \mathrm{g})$, sulfamethoxazole/trimethoprim $(1.25 / 23.75 \mu \mathrm{g})$. Quality control included weekly testing of susceptible Escherichia coli strain ATCC 25,922.

Resistance to any of the 3rd generation cephalosporins (3GC) was used to infer ESBL production. The outcomes (Resistant, Intermediate and Susceptibility i.e. RIS category, Zone of Inhibition measurements and MIC's) from the network of laboratories were captured in MEDITECH-a centralized laboratory information system.

\section{Data acquisition and analysis}

A datafile containing microbiological information (including AST results) of isolates from female urine cultures between January 2016 and December 2017 was exported from MEDITECH. This anonymized datafile contained countrywide information on the age of the patient, hospital location, specimen type, specimen collection date, species/name of the micro-organism found and antimicrobial susceptibility test results based on the RIS classification for every isolate. The RIS determinations were made with WHONET 2019 (VITEK MICs only) using the CLSI M100 ED29:2019 interpretative breakpoints.

\section{Results}

\section{Specimens and culture overview}

The total number of microbiological cultures performed on female urine specimens between 2016 and 2017 was 22,259 with a culture positivity rate of $62.6 \%$ and $60.4 \%$ in the respective 2 years (Table 1 ).

The numbers of urine specimens and cultures were highest in Khomas, Oshana, Oshikoto, and Omusati. These regions recorded over 2,000 cultures in the 2 years combined (Fig. 1).

The majority of isolates were E. coli $(40.7 \%), K$. pneumoniae (6.3\%) and P. mirabilis (5.4\%) by species. Proportionally, all other gram-negatives and grampositives were $5 \%$ and less of the total isolates. The aforementioned three species will thus be referred to as common offending pathogens in this paper. For these

Table 1 Overview of urine cultures performed $(N=22,259)$ at NIP by year

\begin{tabular}{llll}
\hline Urine specimens & $\mathbf{2 0 1 6}$ & $\mathbf{2 0 1 7}$ & $\begin{array}{l}\text { Total } \\
\mathbf{n}(\%)\end{array}$ \\
\hline Culture negative & $3922(37.4)$ & $4664(39.6)$ & $8586(38.6)$ \\
Culture positive & $6555(62.6)$ & $7118(60.4)$ & $13,673(61.4)$ \\
Total & $10,477(100)$ & $11,782(100)$ & $22,259(100)$ \\
\hline
\end{tabular}




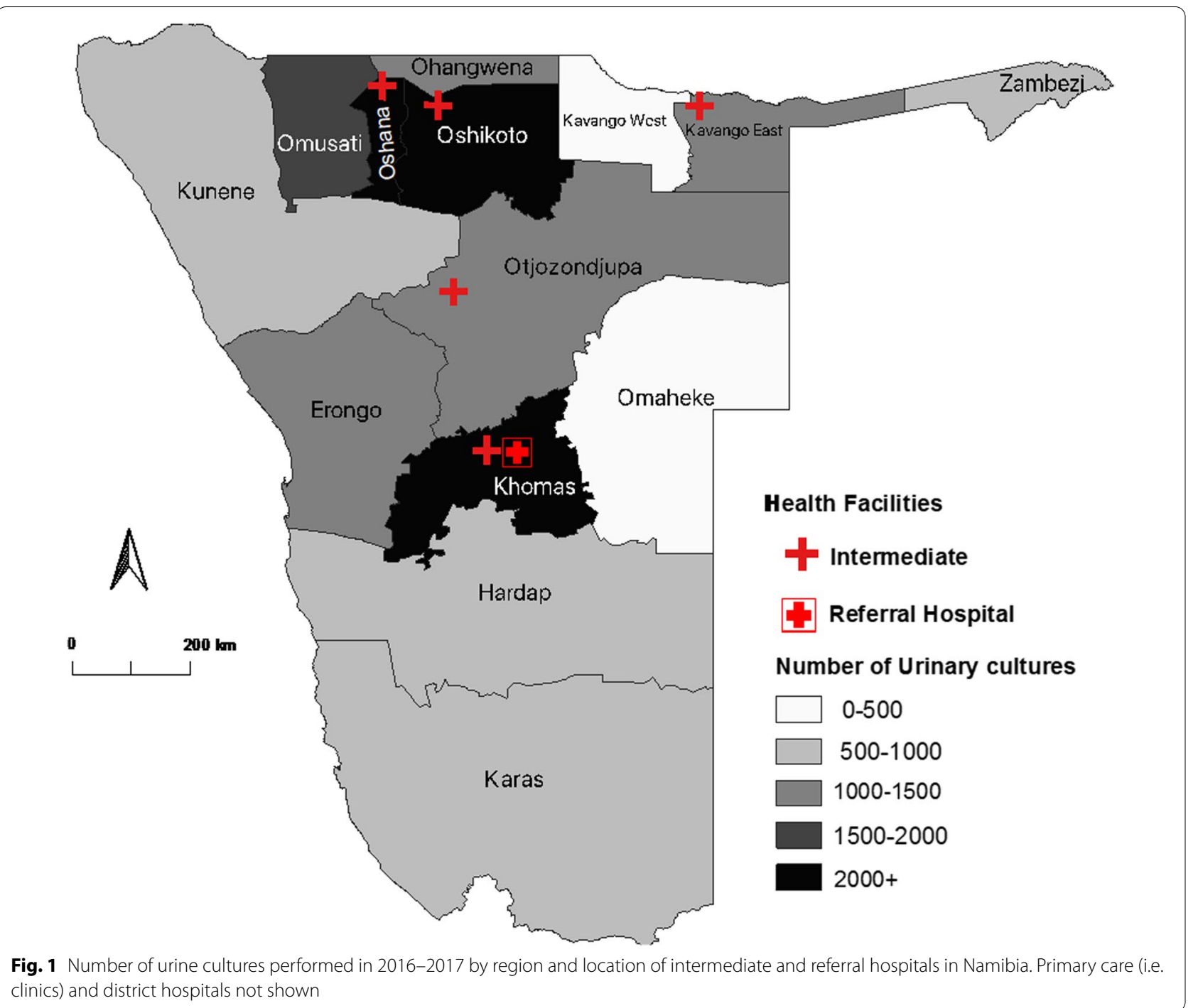

offending pathogens, the proportions were very comparable during the two years (Table 2).

The distribution of the common uropathogens across the regions generally followed the same trend as that of the frequency of urine specimens collected (see Fig. 1). The majority of bacterial organisms were isolated from the capital Khomas region, i.e. more than 20\% of the isolates. The Kavango East, Omusati, Oshana and Oshikoto regions which are predominantly north of the capital region, ranked in the top five of the regions with significantly high isolate counts after the Khomas region.

\section{Patient demographic information}

The age distribution data shows that the median age for UTI patients was between 28 and 32 years (Additional file 1: Supplementary 1), except in the Kavango East region where the
Table 2 Proportions of microbiological findings in 2016-2017

\begin{tabular}{llll}
\hline Microbiological findings & $\begin{array}{l}\mathbf{2 0 1 6} \\
\mathbf{n}(\%)\end{array}$ & $\begin{array}{l}\mathbf{2 0 1 7} \\
\mathbf{n}(\%)\end{array}$ & $\begin{array}{l}\text { Total } \\
\mathbf{n}(\%)\end{array}$ \\
\hline Gram negatives & & & \\
Escherichia coli & $2659(40.6)$ & $2909(40.9)$ & $5568(40.7)$ \\
Klebsiella pneumoniae & $390(6.0)$ & $472(6.6)$ & $862(6.3)$ \\
Proteus mirabilis & $359(5.5)$ & $385(5.4)$ & $744(5.4)$ \\
Other gram negatives & $1436(22)$ & $1321(18.6)$ & $2757(20.2)$ \\
Gram positives & $1030(15.7)$ & $1077(15.1)$ & $2107(15.4)$ \\
Mixed bacterial growth & $278(4.2)$ & $499(7.0)$ & $777(5.7)$ \\
Fungi & $398(6.1)$ & $449(6.3)$ & $847(6.2)$ \\
Clostridium spp & 0 & $4^{*}$ & $4^{*}$ \\
Mycobacteria & $3^{*}$ & 0 & $3^{*}$ \\
Helminthes & $2^{*}$ & $2^{*}$ & $4^{*}$ \\
Total & $6555(100)$ & $7118(100)$ & $13,673(100)$ \\
\hline
\end{tabular}

* Less than $1 \%$ 
median age was 110 . The inter-quartile age range of patients with an E. coli isolate was $23-47$ and 23-45 years in 2016 and 2017, respectively. Furthermore, the three common pathogens were generally isolated from young to middleaged adult females in the age range of 18-52 years. Among the $0-4$ years age group, Klebsiella pneumoniae was proportionally the most common isolate (i.e. $16.9 \%$ and $13.1 \%$ in 2016 and 2017, respectively) whilst Proteus mirabilis was more common in the older age groups (i.e. $>60$ years).

\section{Antimicrobial resistance by antimicrobial group \\ E. coli ß-lactams \pm inhibitor}

E. coli resistance was highest for ampicillin, being $75.8 \%$ in 2016 and $77.7 \%$ in 2017. Amoxicillin-clavulanic acid resistance was $12.3 \%$ and $19.3 \%$ in 2016 and 2017, respectively. From 2016-2017, cefuroxime resistance varied from $18.0 \%$ to $22.4 \%$ and of $3 \mathrm{GCs}$, ceftriaxone resistance was of the same level. ESBL confirmatory tests were performed in one region only and thus the exact ESBL rates could not be given. Resistance to carbapenems was almost non-existent $(<1 \%)$ (Table 3$)$.

\section{Quinolone/fluoroquinolone}

Quinolone resistance, i.e. nalidixic acid resistance, was $38.3 \%$ and $38.5 \%$ in 2016 and 2017, respectively. Whereas ciprofloxacin and ofloxacin resistance was in the range of 15.6-19.3\% during the two consecutive years (Table 3).

\section{Nitrofurantoin}

The first-line empiric antibiotic nitrofurantoin generally showed low resistance rates, ranging from 9.4 to $12.4 \%$ in
2016 and 2017, respectively. However, resistance to nitrofurantoin was exceptional in the Zambezi region, with a resistance rate of $59.2 \%(45 / 76)$ and $48.9 \%(43 / 88)$ in 2016 and 2017, respectively.

\section{Sulfamethoxazole-trimethoprim}

Resistance to sulfamethoxazole-trimethoprim was $81.1 \%$ and $77.2 \%$ in 2016 and 2017, respectively.

\section{Klebsiella pneumoniae and Proteus mirabilis}

Klebsiella pneumoniae resistance to ampicillin was $84.9 \%$ in both years. Amoxicillin-clavulanic acid was $13.8 \%$ and $12.7 \%$ in the two years. Cefuroxime resistance was $29.0 \%$ and $28.6 \%$. K. pneumoniae exhibited resistance to ceftriaxone at $32.7 \%$ and $31.4 \%$. Only one isolate out of 171 isolates tested was found to be resistant to imipenem. (Table 4).

Among P. mirabilis, 3GCs resistance ranged from 8.3 to $11.4 \%$ whereas resistance to imipenem was $5.4 \%$ and 5.6 in the two consecutive years. Nitrofurantoin resistance was $70.8 \%$ and $71.3 \%$ in 2016 and 2017 whereas sulfamethoxazole-trimethoprim was $58.5 \%$ in both years (Table 5).

\section{Discussion}

To our knowledge this is the first report on antimicrobial resistance rates among urinary pathogens in Namibian women. E. coli was found to be the main pathogen with high resistance rates to ampicillin, fluoroquinolones and sulfamethoxazole-trimethoprim. Twenty-two percent of

Table 3 Antimicrobial resistance of E. coli in 2016-2017 in Namibia, 2016-2017

\begin{tabular}{|c|c|c|c|c|c|c|}
\hline \multirow[b]{2}{*}{ Antimicrobials } & \multicolumn{3}{|l|}{$2016(n=2659)$} & \multicolumn{3}{|l|}{$2017(n=2909)$} \\
\hline & $\begin{array}{l}\text { No. of Resistant } \\
\text { isolates }\end{array}$ & $\begin{array}{l}\text { No. of isolates } \\
\text { tested }\end{array}$ & $\%$ Resistant & $\begin{array}{l}\text { No. of Resistant } \\
\text { isolates }\end{array}$ & $\begin{array}{l}\text { No. of isolates } \\
\text { tested }\end{array}$ & \%Resistant \\
\hline Ampicillin & 410 & 541 & 75.8 & 580 & 746 & 77.7 \\
\hline Amoxicillin-Clavulanic acid & 153 & 1245 & 12.3 & 299 & 1551 & 19.3 \\
\hline Piperacillin/Tazobactam & 4 & 112 & 3.6 & 7 & 186 & 3.8 \\
\hline Cephalothin & 481 & 1467 & 32.8 & 564 & 1345 & 41.9 \\
\hline Cefuroxime & 213 & 1186 & 18.0 & 268 & 1195 & 22.4 \\
\hline Ceftriaxone & 83 & 460 & 18.0 & 73 & 332 & 22.0 \\
\hline Ceftazidime & 15 & 67 & 22.4 & 8 & 76 & 10.5 \\
\hline Imipenem & 4 & 470 & 0.9 & 4 & 713 & 0.6 \\
\hline Nalidixic acid & 651 & 1700 & 38.3 & 671 & 1744 & 38.5 \\
\hline Ciprofloxacin & 180 & 935 & 19.3 & 160 & 982 & 16.3 \\
\hline Ofloxacin & 265 & 1699 & 15.6 & 290 & 1790 & 16.2 \\
\hline Gentamicin & 309 & 1734 & 17.8 & 340 & 1819 & 18.7 \\
\hline Nitrofurantoin & 163 & 1730 & 9.4 & 224 & 1803 & 12.4 \\
\hline SXT & 1257 & 1550 & 81.1 & 1031 & 1336 & 77.2 \\
\hline
\end{tabular}


Table 4 Antimicrobial resistance of Klebsiella pneumoniae in Namibia, 2016-2017

\begin{tabular}{|c|c|c|c|c|c|c|}
\hline \multirow[b]{2}{*}{ Antimicrobials } & \multicolumn{3}{|l|}{$2016(N=390)$} & \multicolumn{3}{|l|}{$2017(N=472)$} \\
\hline & $\begin{array}{l}\text { No. of Resistant } \\
\text { isolates }\end{array}$ & $\begin{array}{l}\text { No. of isolates } \\
\text { tested }\end{array}$ & \%Resistant & $\begin{array}{l}\text { No. of Resistant } \\
\text { isolates }\end{array}$ & $\begin{array}{l}\text { No. of isolates } \\
\text { tested }\end{array}$ & \%Resistant \\
\hline Ampicillin & 73 & 86 & 84.9 & 101 & 119 & 84.9 \\
\hline Amoxicillin/Clavulanic acid & 23 & 167 & 13.8 & 32 & 251 & 12.7 \\
\hline Piperacillin/Tazobactam & 0 & 15 & 0 & 0 & 29 & 0 \\
\hline Cephalothin & 81 & 192 & 42.2 & 89 & 215 & 41.4 \\
\hline Cefuroxime & 40 & 138 & 29 & 42 & 147 & 28.6 \\
\hline Ceftriaxone & 18 & 55 & 32.7 & 11 & 35 & 31.4 \\
\hline Ceftazidime & 2 & 5 & 40 & 1 & 7 & 14.3 \\
\hline Imipenem & 0 & 50 & 0 & 1 & 121 & 0.8 \\
\hline Nalidixic acid & 35 & 210 & 16.7 & 58 & 267 & 21.7 \\
\hline Ciprofloxacin & 18 & 96 & 18.8 & 17 & 114 & 14.9 \\
\hline Ofloxacin & 20 & 215 & 9.3 & 29 & 287 & 10.1 \\
\hline Gentamicin & 69 & 217 & 31.8 & 70 & 277 & 25.3 \\
\hline Nitrofurantoin & 50 & 213 & 23.5 & 65 & 280 & 23.2 \\
\hline SXT & 125 & 194 & 64.4 & 127 & 209 & 60.8 \\
\hline
\end{tabular}

SXT: sulfamethoxazole/trimethoprim; \%: percentage

Table 5 Antimicrobial resistance of Proteus mirabilis in Namibia, 2016-2017

\begin{tabular}{|c|c|c|c|c|c|c|}
\hline \multirow[b]{2}{*}{ Antimicrobials } & \multicolumn{3}{|l|}{$2016(N=359)$} & \multicolumn{3}{|l|}{$2017(N=385)$} \\
\hline & $\begin{array}{l}\text { No. of Resistant } \\
\text { isolates }\end{array}$ & $\begin{array}{l}\text { No. of isolates } \\
\text { tested }\end{array}$ & \%Resistant & $\begin{array}{l}\text { No. of Resistant } \\
\text { isolates }\end{array}$ & $\begin{array}{l}\text { No. of isolates } \\
\text { tested }\end{array}$ & \%Resistant \\
\hline Ampicillin & 34 & 88 & 38.6 & 84 & 167 & 50.3 \\
\hline Amoxicillin/clavulanic acid & 13 & 195 & 6.7 & 37 & 259 & 14.3 \\
\hline Piperacillin/tazobactam & 2 & 15 & 13.3 & 0 & 25 & 0 \\
\hline Cephalothin & 27 & 207 & 13 & 46 & 190 & 24.2 \\
\hline Cefuroxime & 20 & 175 & 11.4 & 16 & 168 & 9.5 \\
\hline Ceftriaxone & 6 & 60 & 10 & 3 & 36 & 8.3 \\
\hline Ceftazidime & 1 & 6 & 16.7 & 1 & 4 & 25 \\
\hline Ciprofloxacin & 16 & 136 & 11.8 & 6 & 133 & 4.5 \\
\hline Gentamicin & 37 & 260 & 14.2 & 36 & 273 & 13.2 \\
\hline Imipenem & 3 & 56 & 5.4 & 5 & 90 & 5.6 \\
\hline Nalidixic acid & 49 & 256 & 19.1 & 56 & 268 & 20.9 \\
\hline Nitrofurantoin & 182 & 257 & 70.8 & 191 & 268 & 71.3 \\
\hline Ofloxacin & 21 & 253 & 8.3 & 18 & 273 & 6.6 \\
\hline SXT & 134 & 229 & 58.5 & 110 & 188 & 58.5 \\
\hline
\end{tabular}

SXT: Sulfamethoxazole/Trimethoprim; \%: Percentage

the isolates were resistant to third-generation cephalosporins which is concerning. However, resistance to carbapenems was low.

The empirical drug, nitrofurantoin has demonstrated superiority in our setting.

In our nationwide collection of urine culture specimens, the culture positivity rate of $61.4 \%$ found is somewhat comparable to the $51.2 \%$ positivity found by Rizvi et al. among pregnant women in India [18] or reported from Western countries by Hooton et al. [19]. As the culture practices and guidance of either the laboratories or the clinicians have not changed in Namibia during the recent years, we expect the figures to represent the current situation. There is no universal agreement on the cut-off value that represents a positive urine culture. Across different settings cut-off values are set between $10^{2}$ to $10^{5} \mathrm{CFU} / \mathrm{ml}$ and may potentially overestimate or underestimate culture positivity rates $[20$, 
21]. In Namibia a cut-off value of $\geq 10^{3} \mathrm{CFU} / \mathrm{ml}$ is used. Other factors which have reported to influence culture positivity rates include individual and population level treatment-seeking behaviour [22] and diagnostic methods with variable sensitivity or better Positive Predictive Values (PPV) than traditional culture [21, 23, 24].

The Khomas, Oshana, Omusati and Oshikoto regions had the highest number of positive urinary culture findings. Intermediate-high level (i.e. referral hospital) care facilities are primarily located in the aforementioned regions, but we do not have further information on the distribution of out- and in-patients in our study material.

Gram-negative organisms accounted for at least $70 \%$ of the isolates cultured, with the most common pathogens being E. coli and K. pneumoniae, which is in concordance with the aetiological findings reported elsewhere $[5,22]$. The Global Antimicrobial Surveillance System (GLASS) recommends reporting resistance for priority pathogens, E. coli and K. pneumoniae from urine specimens [14].

We report that young and middle-aged adults are mostly affected by urinary tract infections. This is consistent with the risk age for UTI's that has been reported in other settings elsewhere $[25,26]$. Age shifts to the elderly were noticeable in regions that are primarily rural, particularly the Kavango East Region. The Kavango East region is an economically disadvantaged region. In Namibia, only the elderly are exempted from in-andoutpatient healthcare service fees, which may reflect to health service usage.

High AMR rates $(\sim 80 \%)$ were reported in E.coli against ampicillin and sulfamethoxazole/trimethoprim. This is very similar to that of neighboring South Africa [27]. These antimicrobials should thus only be used in clinical treatment when supported by AST results to minimize the risk of treatment failure. Similar to Kenya, these antibiotics are used in Namibia for respiratory illness and pneumocystis prophylaxis in HIV infected individuals, which may fuel the situation respectively [28].

Resistance rates in the range of $12.3-22.4 \%$ were reported to several antibiotics, namely amoxicillin-clavulanic acid, cefuroxime and gentamicin (Tables 4, 5). Resistance to nalidixic acid is in the range of $38 \%$, whilst ofloxacin resistance remained at $\sim 16 \%$. Nitrofurantoin resistance rates were the lowest being in the range of 9.4-12.4\%.

The Namibia Standard Treatment Guidelines (NSTG) recommends the use of nitrofurantoin and nalidixic acid for cystitis in adults and children, respectively. Intravenous gentamicin and cefuroxime are recommended for upper UTI or complicated presentations [29]. Nitrofurantoin has demonstrated high susceptibility against $E$. coli, whilst nalidixic acid, gentamicin and cefuroxime showed variable but worryingly high resistance rates.
ESBL producers were inferred from 3GCs resistance, and for E.coli the ESBL rates represented 18.0-22.0\% in our study. This is within the global ESBL-resistance ranges of $15-75 \%$ and $28-68 \%$ against cefotaxime reported in 2020 and 2021, respectively [30, 31]. Across Europe, E. coli-3GC resistance ranged from 6.2 to $30.8 \%$ among bacteremic isolates in 2019 [32]. Muriuki et.al. reports a similar finding among $E$. coli uropathogens in Kenya between 2015 and 2018 [33]. Nonetheless an ESBL prevalence of $25 \%$ significantly creates therapeutic problems with ß-lactams and quinolones [34].

In $K$. pneumoniae, likewise to $E$. coli, relatively high resistance levels were observed. Especially, 3GC resistance was noteworthily high (\%R: $32.7 \%$ ). The global cefotaxime resistance ranges stood at $32-62 \%$ and $28-62 \%$ in 2020 and 2021, respectively [30, 31]. In European countries this rate has varied between 4.3 and $75.7 \%$ in 2019 [32]. Fortunately, only one carbapenemase producing isolate among those tested was found.

To our slight surprise, Proteus mirabilis stood as the third most common UTI pathogens with worrying resistance against key antimicrobials. This organism may threaten treatment success with the empiric nitrofurantoin in rural regions due to the high resistance $(>70 \%)$.

We recognize various systematic and methodological limitations which should be considered when interpreting our findings. The Namibian healthcare system lacks a unique patient identifier and the laboratory relies on specimen and requisition numbers for identification and traceability. Patients with multiple specimen submissions could not be identified in order to apply the often recommended first isolate rule to the analysis.

Our records did not document the setting of infection acquisition (out- or in-patient/ward/unit), patient characteristics and other epidemiological information (i.e. pregnancy and other predisposing conditions). We were thus not able to perform sub-group analysis by setting or patient characteristics, which would have allowed more in depth analysis for antimicrobial therapy guidance purposes.

Due to operational and financial constraints, laboratories across the country do not have similar resources or equipment. This may have affected the AST practices performed (including the decision on when and for which antibiotics AST is performed) even though, in general, the same standard operation procedures (SOP) are instructed to be followed in all NIP laboratories. For example, of 5568 E. coli isolates cultured, only approx. $63 \%$ were tested against the first line empirical drug, nitrofurantoin. Also, the semi-automated commercial diagnostic systems such as VITEK are only found at the central main laboratory in Windhoek, while the other laboratories use solely disk diffusion method for 
AST. Consequently, due to possible lack of uniformity in microbiological practices, resistance rates reported may be overestimated or underestimated across sites. There is thus a need for the strengthening of standardization of testing to further increase the reliability of the results.

\section{Conclusion}

This is the first paper to describe the antimicrobial resistance situation of urine isolates in Namibia. Moderate to high resistance levels to several empirical UTI antibiotics were observed, and one fifth of $E$. coli isolates showed third-generation cephalosporin resistance. However, superiority of nitrofurantoin was found, which provides rational support for the usefulness of nitrofurantoin as an empiric therapy regimen for the treatment of urinary tract infections in Namibia.

\section{Abbreviations}

\%R: Percentage resistance; 3GC: Third-generation cephalosporin; 95-95\%: Confidence Interval; AMC: Amoxicillin-clavulanic acid; AMR: Antimicrobial Resistance; AST: Antimicrobial Susceptibility Test; CLSI: Clinical and Laboratory Standards Institute; ESBL: Extended Spectrum-ß-lactamases; IQR: Interquartile range; NA: Missing; SXT: Sulphamethoxazole/trimethoprim.

\section{Supplementary Information}

The online version contains supplementary material available at https://doi. org/10.1186/s13756-022-01066-2.

Additional file 1. Patient age distribution by cultured pathogen and year.

\section{Authors' contributions}

The study was conceptualized by BS, BF, EH. The formal data analysis was done by $\mathrm{EH}$ under the supervision of $\mathrm{J}, \mathrm{AH}, \mathrm{OV}$. All authors were involved in the writing and editing of the manuscript. All authors have also approved the manuscript.

\section{Funding}

Finnish National Agency For Education (Pool KM-18-10822) (EH). University of Turku: University of Turku-University of Namibia (UTU-UNAM) Research collaboration allocation (JV).

\section{Availability of data and materials}

Datasets used and/or analysed during the current study are available from the corresponding author on reasonable request.

\section{Declarations}

Ethics approval and consent to participate

The research proposal was submitted to the Research and Ethics committee of the Ministry of Health and Social Services for approval (Ref:18/3/3 BF). Approval has been granted and data was subsequently obtained from the central NIP repository.

\section{Consent for publication}

Not applicable.

\section{Competing interests}

The authors declare that they have no competing interest.

\section{Author details}

${ }^{1}$ School of Medicine, Faculty of Health Sciences, University of Namibia, Windhoek, Namibia. ${ }^{2}$ Institute of Biomedicine, University of Turku, Turku, Finland.

${ }^{3}$ School of Pharmacy, Faculty of Health Sciences, University of Namibia, Windhoek, Namibia. ${ }^{4}$ Namibia Institute of Pathology, Windhoek, Namibia. ${ }^{5}$ Faculty of Medicine, University of Turku, Turku, Finland. ${ }^{6}$ Department of Clinical Microbiology, Laboratory Division, Turku University Hospital, Turku, Finland.

Received: 24 February 2021 Accepted: 21 January 2022

Published online: 12 February 2022

\section{References}

1. Mattar C, Edwards S, Baraldi E, Hood J. An overview of the global antimicrobial resistance research and development hub and the current landscape. Curr Opin Microbiol. 2020;57:56-61.

2. Islam S, Aldstadt J, Aga D. Global antimicrobial resistance: a complex and dire threat with few definite answers. Hoboken: Wiley; 2019.

3. Schmiemann G, Kniehl E, Gebhardt K, Matejczyk MM, Hummers-Pradier E. The diagnosis of urinary tract infection. Dtsch Aerzteblatt Online. 2010;107(21):361-8. https://doi.org/10.3238/arztebl.2010.0361.

4. Flores-Mireles AL, Walker JN, Caparon M, Hultgren SJ. Urinary tract infections: epidemiology, mechanisms of infection and treatment options. Nat Rev Microbiol. 2015;13(5):269-84. https://doi.org/10.1038/nrmicro3432.

5. John E. Bennett MDM, Dolin R, Blaser MJ. Mandell, Douglas, and Bennett's Principles and Practice of Infectious Diseases: 2-Volume Set [Internet]. Elsevier Health Sciences; 2014. (Mandell, Douglas, and Bennett's Principles and Practice of Infectious Diseases). https://books.google.com.na/ books?id=BseNCgAAQBAJ

6. Zalewska-piątek B, Piątek R. Alternative treatment approaches of urinary tract infections caused by uropathogenic Escherichia coli strains. Acta Biochim Pol. 2019:66:2787.

7. Ny S, Edquist P, Dumpis U, Gröndahl-Yli-Hannuksela K, Hermes J, Kling A-M, et al. Antimicrobial resistance of Escherichia coli isolates from outpatient urinary tract infections in women in six European countries including Russia. J Glob Antimicrob Resist. 2019;17:25-34.

8. Gardiner BJ, Stewardson AJ, Abbott IJ, Peleg AY. Nitrofurantoin and fosfomycin for resistant urinary tract infections: old drugs for emerging problems. Aust Prescr. 2019;42(1):14.

9. Bean DC, Krahe D, Wareham DW. Antimicrobial resistance in community and nosocomial Escherichia coli urinary tract isolates, London 2005-2006. Ann Clin Microbiol Antimicrob. 2008;7(1):13. https://doi.org/10.1186/ 1476-0711-7-13.

10. Karlowsky JA, Kelly LJ, Thornsberry C, Jones ME, Sahm DF. Trends in antimicrobial resistance among urinary tract infection isolates of Escherichia coli from female outpatients in the United States. Antimicrob Agents Chemother. 2002;46(8):2540-5. https://doi.org/10.1128/AAC.46.8.25402545.2002.

11. Bader MS, Loeb M, Brooks AA. An update on the management of urinary tract infections in the era of antimicrobial resistance. Postgrad Med. 2017;129(2):242-58. https://doi.org/10.1080/00325481.2017.1246055.

12. Gandra S, Alvarez-Uria G, Turner P, Joshi J, Limmathurotsakul D, van Doorn HR. Antimicrobial resistance surveillance in low-and middle-income countries: progress and challenges in eight South Asian and Southeast Asian countries. Clin Microbiol Rev. 2020;33(3):e00048-e119.

13. Tacconelli E, Sifakis F, Harbarth S, Schrijver R, van Mourik M, Voss A, et al. Surveillance for control of antimicrobial resistance. Lancet Infect Dis. 2018;18(3):e99-106.

14. World Health Organization. Global Antimicrobial Resistance Surveillance System (GLASS) Report: Early Implementation 2020. 2020.

15. Ministy of Health and Social Services. Namibian Antimicrobial Resistance National Action Plan. 2017.

16. Sheehama J, Van ZL, Hakuuria V. An assessment of the quality of antibiotic prescription in Katutura health centre. Khomas region J Pharmacol Ther Res. 2018;2(3):13-6.

17. Pereko DD, Lubbe MS, Essack SY. Antibiotic use in Namibia: prescriber practices for common community infections. South African Fam Pract. 2015;57(4):231-5. https://doi.org/10.1080/20786190.2015.1024021. 
18. Rizvi M, Khan F, Shukla I, Malik A. Rising prevalence of antimicrobial resistance in urinary tract infections during pregnancy: necessity for exploring newer treatment options. J Lab Physicians. 2011;3(02):98-103.

19. Hooton TM, Roberts PL, Cox ME, Stapleton AE. Voided midstream urine culture and acute cystitis in premenopausal women. N Engl J Med. 2013;369(20):1883-91.

20. Heytens S, De Sutter A, Coorevits L, Cools P, Boelens J, Van Simaey L, et al. Women with symptoms of a urinary tract infection but a negative urine culture: PCR-based quantification of Escherichia coli suggests infection in most cases. Clin Microbiol Infect. 2017;23(9):647-52.

21. Chin TL, McNulty C, Beck C, MacGowan A. Antimicrobial resistance surveillance in urinary tract infections in primary care. J Antimicrob Chemother. 2016;71(10):2723-8. https://doi.org/10.1093/jac/dkw223.

22. Mohammed MA, Alnour TMS, Shakurfo OM, Aburass MM. Prevalence and antimicrobial resistance pattern of bacterial strains isolated from patients with urinary tract infection in Messalata Central Hospital. Libya Asian Pac J Trop Med. 2016;9(8):771-6.

23. Mejuto P, Luengo M, Díaz-Gigante J. Automated flow cytometry: an alternative to urine culture in a routine clinical microbiology laboratory? Sanguinetti M, editor. Int J Microbiol. 2017;2017:8532736. https://doi.org/ 10.1155/2017/8532736.

24. Sugianli AK, Ginting F, Kusumawati RL, Pranggono EH, Pasaribu AP, Gronthoud F, et al. Antimicrobial resistance in uropathogens and appropriateness of empirical treatment: a population-based surveillance study in Indonesia. J Antimicrob Chemother. 2017;72(5):1469-77. https://doi. org/10.1093/jac/dkw578.

25. Gupta K, Grigoryan L, Trautner B. Urinary tract infection. Ann Intern Med. 2017;167(7):ITC49. https://doi.org/10.7326/AITC201710030.

26. Medina M, Castillo-pino E. An introduction to the epidemiology and burden of urinary tract infections. Ther Adv Urol. 2019;11:3-7.

27. Kubone PZ, Mlisana KP, Govinden U, Abia AL, Essack SY. Antibiotic susceptibility and molecular characterization of uropathogenic Escherichia coli associated with community-acquired urinary tract infections in urban and rural settings in South Africa. Trop Med Infect Disease. 2020;5

28. Maina D, Omuse G, Revathi G, Adam RD. Spectrum of microbial diseases and resistance patterns at a private teaching hospital in Kenya: implications for clinical practice. PLoS ONE. 2016;11(1):e0147659. https://doi.org/ 10.1371/journal.pone.0147659.

29. Ministry of Health and Social Services. Namibia Standard Treatment Guidelines. 2011;355.

30. World Health Organization. Global antimicrobial resistance surveillance system (GLASS) report: early implementation 2020 [Internet]. Geneva PP_Geneva: World Health Organization. https://apps.who.int/iris/handle/10665/332081

31. World Health Organization. Global antimicrobial resistance and use surveillance system (GLASS) report: 2021 [Internet]. Geneva PP_Geneva: World Health Organization. https://apps.who.int/iris/handle/10665/ 341666

32. European Centre for Disease Prevention and Control. Surveillance atlas of infectious diseases [Internet]. 2019 [cited 2021 Oct 4]. http://atlas.ecdc. europa.eu/public/index.aspx

33. Muriuki CW, Ogonda LA, Kyanya C, Matano D, Masakhwe C, Odoyo E, et al. Phenotypic and genotypic characteristics of uropathogenic Escherichia coli isolates from Kenya. Microb Drug Resist. 2021;

34. Shakya P, Shrestha D, Maharjan E, Sharma VK, Paudyal R. ESBL production among E. coli and Klebsiella spp. causing urinary tract infection: a hospital based study. Open Microbiol J. 2017;11:23-30.

\section{Publisher's Note}

Springer Nature remains neutral with regard to jurisdictional claims in published maps and institutional affiliations. 